\title{
The parrot, the pince-nez and the pleochroic halo
}

\author{
D. Weaire and S. Coonan
}

$T^{n}$ the midst of the chaos of the 1916 Easter Rising in Dublin, a lone figure ventured forth from the defences of Trinity College, in search of fresh intelligence and cigarettes for his comrades. Whether by good fortune or the poor marksmanship of his enemy, John Joly survived this experience to become the grand old man of science in the independent state that he opposed. He is mostly remembered as a geologist but, as one obituary acutely observed, he was essentially a physicist.

Joly had a distinguished continental pedigree too elaborate to be recounted here, but he was born in Ireland and educated in Dublin. He was no great scholar in his youth and in another time he might not have prospered as a scientist. But that was the age of Kelvin and Edison, when the young man's interest in practical devices could secure him a prominent place in a list drawn up by the magazine Inventors and Inventions. This was just after he had graduated in engineering. He was already embarked on a remarkable surge of publication and patenting of physical instrumentation. Of the many instruments that he produced, the meldometer, the aphorometer and the steam calorimeter are long forgotten, but Joly's photometer will be familiar to many. While he progressed from Assistant in engineering to a similar position in physics, he contributed to a lively interdisciplinary community, whose doyen was the ebullient George Francis Fitzgerald.

The most promising of those inventions was a new method of colour photography, based on filters made up of lines of different colours. This enabled the taking of pictures in a single shot and their viewing by projection. The method was commercialised as the Joly Process, but a legal dispute arose with a Chicago inventor who was able to claim priority under US law. Technically Joly won the case, but it seems to have been a pyrrhic victory and his process was soon overtaken by others.
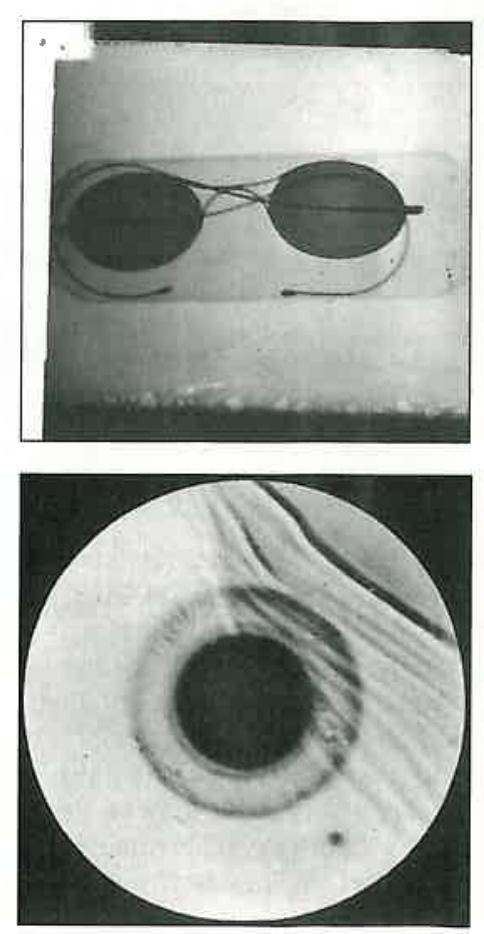

When we began some years ago to gather together the surviving records and lantern slides from that period, we visited the curator of Trinity's geology museum. From a cardboard box he pulled a small parrot which was to become very familiar to us, as Joly's favourite subject. It had survived many years of neglect, and turned up in a cleaner's cupboard.

Unfortunately most of his subjects were no more dramatic or dynamic than the stuffed parrot - the attractions of conventional still life to a photographic pioneer are irresistible. A black-andwhite photograph that he took at much the same time, very soon after the announcement of the discovery of X-rays, is much more striking. It shows, within its wooden case, the pince-nez that became one of his personal trademarks. Another was his motor-bike. All in all, he cut the kind of eccentric professorial figure that is much prized in certain universities.

Early in life he developed a love of the outdoors, exploring the Alps in the Victorian fashion, and everywhere stooping to collect minerals. Many of his instruments were for the analysis of such specimens. For example, the meldometer consisted essentially of a platinum strip upon which small crystals could be placed, electrically heated and viewed, in order to determine their precise melting points. Such interests drew him towards geology and he became professor of that subject.

Joly brought to geology a keen appreciation of the importance of the exciting new subject of radioactivity and nuclear physics, and he explored its implications

over two decades of research, expressed in several books. In particular, he was the first to correctly interpret pleochroic haloes, strange circular patterns in rocks such as mica. In three dimensions they are spherical. They are due to the decay of emitted alpha particles, whose lifetimes dictate their ranges in the material and hence radius of each circle. These radii can thus be identified with the radioactive isotope responsible for the emission. Some of the data defeated immediate categorisation, and Joly thought that he had discovered a new element. This was to be named Hibernium. Alas, it turned out to be Samarium, and Ireland remains unrepresented in the periodic table of the elements.

Pleochroic haloes are back in the news today. Creationists are arguing that some of them offer evidence for the recent divine creation of the universe. Joly himself would have enjoyed the argument he was one of a long line of scientists who tried to estimate the age of the earth, and came up with 100 million years.
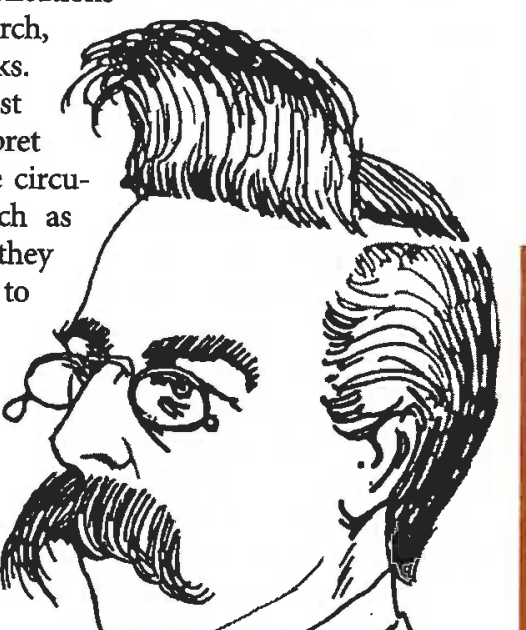